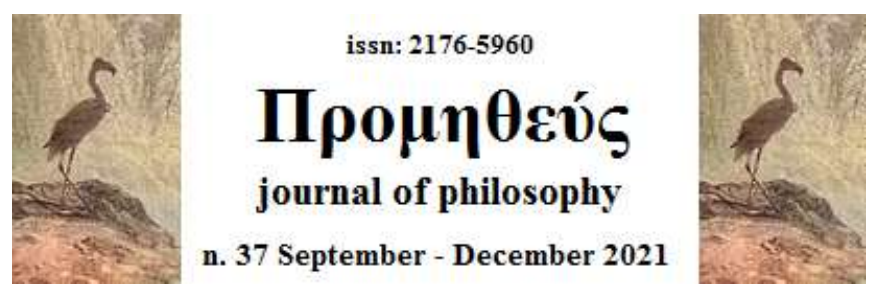

\title{
DESENVOLVIMENTO SUSTENTÁVEL E A TEORIA RAWLSIANA DA JUSTIÇA
}

\author{
RÉGIS CANALE DOS SANTOS ${ }^{1}$ \\ SANDRO MARCOS GODOY ${ }^{2}$
}

\begin{abstract}
RESUMO: O direito ao desenvolvimento encontra-se previsto em diversos diplomas internacionais e na própria Constituição Federal de 1988, sendo considerado um direito humano pertencente à terceira geração dos direitos humanos, preocupando-se com as futuras gerações, enquadrando-se no direito à solidariedade. Juntamente com a ideia de desenvolvimento deve-se acrescer a sustentabilidade que buscar conciliar os aspectos econômico, social, cultural e ambiental para satisfazer a atual geração, contudo, sem comprometer a fruição para as futuras gerações. O direito ao desenvolvimento sustentável, portanto, é um instrumento para se proporcionar uma melhor qualidade de vida a todos as pessoas, devendo o Estado buscá-lo, por se tratar de um dos objetivos da República Federativa do Brasil, por meio de planejamento. O desenvolvimento econômico, ao se buscar a justiça social, remete a teoria da justiça proposta por Jonh Rawls em que uma sociedade bem organizada satisfaz os princípios da justiça quando forem coletivamente racionais a partir da perspectiva da posição original, sob o manto do véu da ignorância. Adota-se, para fins da investigação, a dedução e a análise crítica, seguidas de pesquisa bibliográfica estrangeira e nacional.
\end{abstract}

PALAVRAS-CHAVE: Desenvolmento; planejamento; teoria da justiça.

ABSTRACT: The right to development is foreseen in several international diplomas and in the Federal Constitution of 1988, being considered a human right belonging to the third generation of human rights, concerned with future generations, framing the right to solidarity. Together with the idea of development, sustainability must be added, seeking to reconcile the economic, social, cultural and environmental aspects to satisfy the current generation, however, without compromising the enjoyment for future generations. The right to sustainable development, therefore, is an instrument to provide a better quality of life for all people, and the State should seek it, as it is one of the

\footnotetext{
${ }^{1}$ Doutorando em Direito pelo Programa de Pós Graduação em Direito da Universidade de Marília UNIMAR /SP. Especialista em Direito Civil e Processual Civil. Oficial de Registro de Imóveis de Pereira Barreto. E-mail: cartorio.regis@gmail.com

${ }_{2}^{2}$ Pesquisador e Professor permanente no programa de Mestrado e Doutorado, graduação na Universidade de Marília-SP (UNIMAR). Pós-doutor em Direito pela Università degli Studi di Messina, Itália, Doutor em Direito - Função Social do Direito pela Faculdade Autônoma de Direito (FADISP), Mestre em Direito - Teoria do Direito e do Estado pelo Centro Universitário Eurípides de Marília (UNIVEM) Email: sandromgodoy@,uol.com.br. Orcid: https//orcid.org/0000-0001-8749-395X.
} 
objectives of the Federative Republic of Brazil, through planning. Economic development, when seeking social justice, refers to the theory of justice proposed by Jonh Rawls in which a well-organized society satisfies the principles of justice when they are collectively rational from the perspective of the original position, under the veil of ignorance. For the purposes of the investigation, deduction and critical analysis are adopted, followed by foreign and national bibliographic research.

KEYWORDS: Development; planning; theory of justice.

\section{INTRODUÇÃO}

O direito ao desenvolvimento é considerado um direito humano inalienável, tendo sido reconhecido por diversos diplomas internacionais e também pela Constituição Federal de 1988. Busca-se, por meio do desenvolvimento, uma melhora na qualidade de vida das pessoas, devendo o Estado proporcionar condições para isso.

O presente trabalho tem por escopo analisar o direito ao desenvolvimento econômico previsto como objetivo da República Federativa do Brasil e a necessidade de interpretá-lo conjuntamente com o princípio da sustentabilidade. Surge, assim, o desenvolvimento sustentável que nada mais é do que um modelo que busca o equilíbrio entre os aspectos político, social, cultural e ambiental, satisfazendo as necessidades da atual geração, sem, contudo, comprometer a fruição das futuras gerações. Para tanto, o Estado deve se valer de planejamento, estabelecendo, assim, as diretrizes e bases do desenvolvimento nacional equilibrado.

Assim sendo, inicia-se com um esboço histórico do surgimento do direito ao desenvolvimento e o seu significado, evidenciado a dificuldade da sua conceituação e delimitação, optando, neste trabalho, pelo desenvolvimento econômico, abordando-se, também, a premissa do planejamento para o seu desiderato. De fato, o desenvolvimento econômico não pode ser considerado um fim em si, mas, sim, um instrumento para atingir outras finalidades, sendo, assim, necessária a sustentabilidade econômica.

E, por fim, será analisada a busca do desenvolvimento econômico e a sustentabilidade com base nas premissas da teoria da justiça de Jonh Rawls que trouxe um novo fôlego à filosofia política e produziu um dos mais importantes debates a respeito da justiça, cujas ideais encontram-se assentadas na justiça por equidade ao se estabelecer um estado inicial do contrato social a partir de uma posição original.

\section{DIREITO AO DESENVOLVIMENTO}


A Constituição Federal de 1988 prevê o direito ao desenvolvimento em seu preâmbulo e o reiterou no artigo $3^{\circ}$, ao estabelecer os objetivos fundamentais da República Federativa do Brasil. Não obstante o direito ao desenvolvimento conste no rol dos objetivos fundamentais, não há dúvida que se trata também de um direito fundamental.

O direito ao desenvolvimento não era uma matéria muito explorada pelos doutrinadores, tendo despertado o interesse a tal tema apenas na década de 1960 que foi marcada pela descolonização de diversos países, mormente na África e na Ásia.

Com a polarização do conflito econômico, decorrente da Guerra Fria, tendo, por um lado, o socialismo, calcado pela então União Soviética, e, por outro, pelo liberalismo, fundamentada pelos Estados Unidos da América, surgiu o empenho de se elaborar nos países do Terceiro Mundo "uma identidade cultural própria propondo direitos de identidade cultural coletiva, como o direito ao desenvolvimento" (LAFER, 1999, p. 177).

Nesse período, portanto, de acordo com Antônio Celso Alves Pereira, foi a primeira vez que se ventilou o tema pelo então Cardeal Etienne Duval, arcebispo de Arghel, que, numa mensagem de ano novo à população de Senegal, no dia $1^{\circ}$ de janeiro de 1969, proclamou o direito ao desenvolvimento dos países do Terceiro Mundo (PEREIRA, 1992, p. 29).

Na década seguinte, em 1977, a Comissão de Direitos Humanos das Nações Unidas, por meio da Resolução 4, XXXIII, reconheceu, pela primeira vez, o direito ao desenvolvimento. Ato contínuo, em 1979, a mesma comissão, reforçando a existência a esse direito, declarou-o como uma prerrogativa tanto das nações como dos indivíduos.

Em seguida, nos idos de 1982, adotou-se a Resolução 37/199/18/1982, pela Assembleia Geral das Nações Unidas, a qual reconheceu o direito ao desenvolvimento como um direito humano inalienável. Por fim, a Resolução 41/128, de 04 de dezembro de 1986, proclamou a Declaração sobre o Direito ao Desenvolvimento. O referido ato ainda não foi ratificado pelo Brasil, contudo, o seu conteúdo inspirou a elaboração de diversos outros ato, inclusive, a Constituição Federal de 1988.

A par desses documentos, registre-se que houve outros no mesmo sentido, tais como a Carta Africana de Direitos Humanos e dos Povos, da Carta da Organização dos Estados Americanos, na Carta das Nações Unidas e nos Pactos Internacionais de Direitos Humanos. 
Esses diplomas internacionais consideram o Direito ao Desenvolvimento um direito humano inalienável em face do qual todos os seres humanos e todos os povos têm o direito de participar, de contribuir e de gozar do desenvolvimento econômico, social, cultural e político, no qual todos os direitos humanos e liberdades fundamentais se possam plenamente realizar.

Nota-se, assim, que se trata de um direito demasiado amplo, com diversos aspectos, que não foi delimitado pelo constituinte originário ao estabelecê-lo no artigo $3^{\circ}$, devendo-se se valer dos valores axiológicos do próprio texto constitucional para preencher seu conteúdo. Parece-me, contudo, que o desenvolvimento deve ser buscado nas esferas social, política e econômica. No presente artigo dar-se-á ênfase ao desenvolvimento econômico.

O artigo 174 da Constituição Federal, que trata da ordem econômica e financeira, demonstra que o Estado se encontra presente no setor econômico. Outrora prevalecia a concepção da ausência total do Estado na economia, no entanto, essa visão não prevalece mais.

Eros Roberto Grau explica que:

Esta suposição subjaz nas afirmações de que à ordem jurídica liberal sucede uma ordem jurídica intervencionista. E, ainda que isso, muitas vezes, não seja explicitamente declarado, o que marcaria essa sucessão seria a ampliação dos contornos da ordem jurídica liberal, decorrente da 'regulação' da ordem econômica (GRAU, 2018, p. 61).

Em seguida, continua o mencionado doutrinador que a ordem jurídica liberal confirmaria, de maneira espontânea, uma ordem social, ao passo que a concepção intervencionista provocaria uma ordem social imposta. Seria a exclusão do natural para o artificial (GRAU, 2018). Mesma reflexão foi feita por Luis Afonso Heck ao asseverar a passagem de um Estado ausente para um Estado presente no setor econômico (HECK, 2000, P. 24).

Paulo Henrique Rocha Scott conclui que embora tenha sido adotado o modelo capitalista, denota-se, outrossim, a finalidade de construção de um modelo de Estado Social, definindo-o como um modelo econômico de bem estar (SCOTT, 2000).

O direito ao desenvolvimento econômico é um direito fundamental em que as riquezas e os bens de produção nacionais deve proporcionar uma qualidade de vida à toda população. Por se tratar de um Estado intervencionista, infere-se que a produção de riquezas funda-se no princípio distributivo, conciliando, dessa forma, a ordem econômica com a ordem social. 
De fato, o desenvolvimento econômico, repita-se, deve proporcionar uma melhor qualidade vida a todos a população da Nação, sendo certo que a renda per capita não pode ser utilizado para sua aferição por não ser um método apropriado para tanto. É uma visão simplista de uma questão muito complexa, ao dividir o produto interno bruto por sua população.

Não obstante se tratar de um índice muito utilizado, na verdade esconde muitas disparidades, pois pode haver um país com uma alta renda per capita mas com alto índice de concentração de renda e desigualdade social. Por outro lado, pode existir um país com baixa renda per capita com uma boa distribuição da renda, sem concentração, minimizando, destarte, a desigualdade social.

Nesse sentido, Amartya Sen escreve que:

Os fins e os meios do desenvolvimento requerem análise e exame minuciosos para uma compreensão mais plena do processo de desenvolvimento; é sem dúvida inadequado adotar como nosso objetivo básico apenas a maximização da renda ou da riqueza, que é, como observou Aristóteles "meramente útil e em proveito de alguma outra coisa". Sendo assim, o desenvolvimento deve estar relacionado sobretudo com a melhora da vida que levamos e das liberdades que desfrutamos (SEN, 1999, p. 54).

Nota-se, portanto, que o direito ao desenvolvimento é um direito fundamental que, além de ser um dos objetivos da República Federativa do Brasil, tem sua eficácia plena e imediata, vinculando os três poderes do Estado em adotar políticas pública que atinjam esse desiderato. Aliás, registre-se que, ao se comparar, os objetivos da República Federativa do Brasil com os princípios da ordem econômica, muitos se equiparam, uma norma reforçando outra.

Para conseguir atingir o desenvolvimento nacional e, de maneira reflexa, reduzir a desigualdade, erradicação da pobreza e da marginalização e a busca do pleno emprego, o Estado, quer participando excepcionalmente no mercado, quer como mero regulador, deve se valer do planejamento.

O preceito relativo ao planejamento encontra-se previsto no parágrafo primeiro do artigo 174 ao dispor que a lei deverá estabelecer as diretrizes e bases do planejamento do desenvolvimento nacional equilibrado, o qual incorporará e compatibilizar os planos nacionais e regionais de desenvolvimento.

Eros Roberto Grau adverte que o planejamento refere-se ao desenvolvimento nacional e não o planejamento da economia ou planejamento da atividade econômica. São suas palavras: 
São inconfundíveis, de um lado o planejamento da economia centralização econômica, que importa a substituição do mercado, como mecanismo de coordenação do processo econômico, pelo plano - de outro o planejamento técnico de ação racional, cuja compatibilidade com o mercado é absoluta (GRAU, 2018, p. 300).

Assim, o planejamento deverá ser feito pela União, por meio do Poder Executivo, abrangendo aspectos nacionais e regionais de desenvolvimento econômico e social, com a plena participação Congresso Nacional, por meio dos representantes eleitos pelo povo. O plano nacional será executado pela União e os planos regionais serão executados por ela em concurso com os órgãos estatuais.

A competência do referido planejamento é da União, conforme o artigo 21, inciso IX, da Constituição Federal, que prescreve que a ela elaborar e executar planos nacionais e regionais de ordenação do território e de desenvolvimento econômico e social.

Deve-se, portanto, valer-se de dados estatísticos reais e profundos da sociedade brasileira, em todas as regiões, para identificar os problemas e as necessidades sociais e econômicas para elaborar um plano efetivo. Não se busca um desenvolvimento imediato. O planejamento deve ser prospectivo e considerar o médio e o longo prazo, pensando nas atuais e nas futuras gerações.

Carla Abrantkoski Rister, valendo-se do escólio de Fábio Konder Comparato, afirma que o desenvolvimento, por meio do planejamento, é "um processo de longo prazo, induzido por políticas públicas ou programas de ação governamental em três campos interligados: econômico, social e político" (RISTER, 2007, p. 56)

O planejamento é a forma de ação racional caracterizada pela previsão de comportamentos econômicos e sociais futuros, pela formulação explícita de objetivos e pela definição de meios de ação coordenadamente dispostos (GRAU, 2018, p. 337).

No tocante ao desenvolvimento e, notadamente, ao planejamento, a Constituição Federal é dirigente, referindo-se ao ideal a ser concretizado, caracterizando-se normas programáticas a serem executadas. André Ramos Tavares explica que constituição dirigente reflete numa necessidade de atuação estatal, consagrando a igualdade substancial, bem como os direitos sociais (TAVARES, 2002, p. 207).

Gomes Canotilho refuta a identificação das normas programáticas como sendo mera intenção declaratório. Para ele são verdadeiras "exortações morais" e "apelos ao legislador" (CANOTILHO, 1981, P. 11-12). 
Justamente pelo desenvolvimento ter uma visão prospectiva e não retrospectiva é que se reconhece que o Direito já não se constata apenas com a representação da ordem estabelecida e a defesa do presente, mas também a formulação de uma ordem futura (GRAU, 2018).

O planejamento configura-se, assim, no direito de terceira dimensão. Pedro Lenza ensina que: “Os direitos da $3^{\text {a }}$ dimensão são direitos transindividuais, isto é, direitos que vão além dos interesses do indivíduo; pois são concernentes à proteção do gênero humano, com altíssimo teor de humanismo e universalidade" (LENZA, 2019, p. 1158).

Surge, portanto, um novo dever ao Estado. Ao lado da função legiferante, da função jurisdicional e da função administrativa, na clássica separação dos poderes de Montesquieu, urge uma nova, qual seja: a função de planejar.

\section{DESENVOLVIMENTO SUSTENTÁVEL}

O termo sustentabilidade comumente é associado às questões ambientais, no sentido de manter um equilíbrio entre o desenvolvimento econômico e a exploração dos recursos naturais. Com efeito, o princípio da sustentabilidade busca a ponderação de dois direitos fundamentais, de um lado o direito à livre iniciativa e, de outro, o direito ao meio ambiente saudável.

No entanto, a sustentabilidade não pode se circunscreve apenas à temática ambiental, sendo certo afirmar que o termo é demasiado amplo e complexo, possuindo aplicabilidade em vários ramos do direito.

Paulo de Oliveira Pinto Coelho e André Fabiano Guimarães de Araújo, nesse mesmo diapasão, sustentam que:

... busca-se evidenciar a sustentabilidade em seu caráter sistêmicoconstitucional, o que implica uma compreensão interdisciplinar desse princípio basilar não somente no viés ambiental, mas também na perspectiva econômico-empresarial e social, numa visão que se quer integrada e interativa desses âmbitos, quando alçados ao plano constitucional (COELHO; ARAÚJO, 2011, p. 213)

A Organização da Sociedade Civil de Interesse Público (OSCIP) CATALISA, que tem por finalidade catalisar, implementar e difundir práticas inovadoras da síntese Cooperação e Sustentabilidade para grupos, organizações públicas e privadas e comunidades, por meio de oficinas, cursos de qualificação, programas de assessorias, 
desenvolvimento de projetos e materiais educativos, conceitua desenvolvimento sustentável da seguinte forma:

Define-se por Desenvolvimento Sustentável um modelo econômico, político, social, cultural e ambiental equilibrado, que satisfaça as necessidades das gerações atuais, sem comprometer a capacidade das gerações futuras de satisfazer suas próprias necessidades (CATALISA, 2020)

Outrossim, a sustentabilidade, por se tratar de um assunto transnacional e de suma importância, por abranger direito difusos, já foi objeto de discussão pela Organização das Nações Unidas, no relatório Brundtland, o qual concluiu que:

Em essência, o desenvolvimento sustentável é um processo de transformação no qual a exploração dos recursos, a direção dos investimentos, a orientação do desenvolvimento tecnológico e a mudança institucional se harmonizam e reforçam o potencial presente e futuro, a fim de atender às necessidades e aspirações humanas (ONU, 1991, p. 49)

Nota-se, assim, que a sustentabilidade busca o equilíbrio entre a satisfação das necessidades atuais e sua preservação para que as futuras gerações também possam dela usufruir. É, em outras palavras, a análise das atitudes atuais que podem refletir no futuro. A sustentabilidade deve ter como parâmetro todos os temas que possam interferir nas próximas gerações, compreendendo os aspectos econômicos, políticos, sociais, culturais e ambientais.

Nenhum dos alicerces acima enunciados podem ser analisados de forma isolada, no presente, sem levar em consideração as suas projeções no futuro. Pelo contrário, todos devem, necessariamente, serem confrontados, buscando a satisfação atual e salvaguardando-os para as próximas gerações.

A sustentabilidade no aspecto econômico busca o equilíbrio entre a utilização de recursos naturais e a produção de riqueza (COELHO; ARAÚJO, 2011). O desenvolvimento com sustentabilidade deve ter como fundamento o critério pluralista e o solidário. Aliás, o contrário, além de não atender ao valor axiológico da Magna Carta em relação à promoção e respeito a dignidade humana, compromete, outrossim, o equilíbrio econômico (ANDRADE JUNIOR, 2010, p. 271-290).

Portanto, a sustentabilidade econômica pode ser compreendida como uma forma de “...estabelecer que o bem-estar aumenta quando melhora o padrão de vida de um ou mais indivíduos sem que decaia o padrão de vida de outro indivíduo e sem que diminua o estoque de capital natural ou o produzido pelo homem" (NOBRE; AMAZONAS, 2002, p. 35). 
Lafayete Josué Petter ensina que o desenvolvimento econômico: “... não pode ser posto a serviço tão somente de um desenvolvimento obtido a qualquer preço, isto é, com sacrifícios que importem em um processo de exclusão crescente" (PETTER, 2011, p. 92).

Em seguida, o mesmo doutrinador arremata que:

Há de se partilhar uma razoável distribuição dos benefícios desse processo de crescimento. O nosso País apresenta problemas de desigualdade acentuada, tanto social como regionalmente. A melhoria das condições sociais há de ser ao mesmo tempo em que se promove desenvolvimento econômico (PETTER, 2011, p. 93)

Nota-se que sempre haverá um conflito entre a ordem econômica e a ordem social. Justamente por isso exige-se uma intervenção do Estado para uma compatibilização das duas ordens. Na busca incessante do desenvolvimento econômico, sem o filtro do aspecto social, pode suceder a implementação de atividades sem sustentabilidade.

A sustentabilidade, em seu aspecto social, não implica na eliminação da livre iniciativa. Pelo contrário, traz uma nova perspectiva, imprimindo um caráter mais instrumental ao princípio da livre iniciativa.

É necessária, portanto, uma participação estatal para dirigir a economia e promover o desenvolvimento nacional por meio dos mecanismos previstos pelo poder constituinte com o escopo de manter o equilíbrio do sistema.

Com efeito, registre-se que a ordem econômica brasileira funda-se na valorização do trabalho humano e da livre iniciativa com o intuito de proporcionar uma existência digna consoante os preceitos da justiça social.

Assim, os princípios da ordem econômica, previstos no artigo 170 da Constituição Federal, fixam uma norte para a atividade econômica, no entanto, repitase, esta tem sua fundamentação na concretização de direitos humanos, com bem-estar a todos e redução da desigualdade, dentre outros, conforme os objetivos da República Federativa do Brasil.

Nessa compatibilização entre o direito econômico e o direito social surge a Teoria do Capitalismo Humanista, de Ricardo Hasson Sayeg, de modo que o capitalismo encontra-se visceralmente ligado aos direitos humanos, sendo que, nas palavras dele, o sentido do capitalismo humanista é: "uma regência jurídica do capitalismo pelo Direito Fraterno que impõe a aplicação multidimensional dos diretos humanos na ordem econômica" (SAYEG, 2011, p. 185). 
Existem duas forças contrapostas que tentam se excluir mutuamente. A intervenção do Estado, portanto, busca conciliar ambas as forçar, maximizando-se os resultados de cada uma. Uma controla a outra para que não se exceda. Uma regra de pesos e contrapesos.

O doutrinador acima sintetiza da seguinte forma:

Sua lógica impositiva é que, embora capitalista, o Planeta será tanto mais livre, evoluído, sustentável e civilizado, quando maior e mais abrangente for a real concretização multidimensional dos direitos humanos com vistas ao seu correspondente objetivo da dignidade da pessoa humana, o que, em absoluto significa paternalismo ou demagogia (SAYEG, 2011, p. 273).

A redução da desigualdade, em todos os seus aspectos, numa decorrência direta do princípio da dignidade da pessoa humana, impõe que a ordem econômica compatibilize-se com a ordem social. O desenvolvimento econômico produz a produção de bens e de serviços e o desenvolvimento social determina a divisão das riquezas promovidas por aquele. Ao se compatibilizar ambos desenvolvimentos atingir-se-á a dignidade da pessoa humana e, por conseguinte, a sustentabilidade.

Com efeito, no capítulo da ordem econômica denota-se o conflito entre princípios, todos com conotação constitucional. Não se pode dizer que um seja mais importante que outro. Deve-se fazer uma exegese buscando o equilíbrio entre eles, extraindo uma interpretação consentânea com os valores axiológicos previstos na Magna Carta, sem exclusão de um por outro. Há, portanto, de se fazer uma ponderação entre eles.

Assim, o direito fundamental da propriedade privada confronta-se com o princípio da função social da propriedade; a livre iniciativa esbarra-se na proteção dos consumidores; a livre iniciativa por vezes confronta com a redução da desigualdades sociais, assim por diante, cabendo, ao exegeta, extrair um interpretação equilibrada, valendo-se de todo o sistema.

Não se deve, portanto, um princípio excluir outro. Dessa forma, o desenvolvimento econômico é importante, porém, isso não significa que direitos sociais sejam suprimidos. O crescimento econômico é desejável, contudo, deve-se buscar a redução da desigualdade que é um corolário da sustentabilidade.

Jaqueline Michels Bilhava esclarece que: "a concretização caracteriza uma das facetas do fenômeno interpretativo, que diz respeito à realizabilidade (à praticidade) da norma, ou seja, à sua aplicabilidade a um caso concreto" (BILHALVA, 2005, p. 106). 
Assim sendo, verifica-se que a busca da sustentabilidade, também serve como contrapeso à atividade econômica, tornando o sistema equilibrado e coeso e em conformidade com os objetivos da República Federativa do Brasil. O Estado deve se valer de instrumentos legais e de políticas públicas para proporcionar, ao mesmo tempo, desenvolvimento econômico e sustentabilidade.

\section{POSSIBILIDADE DA EXISTÊNCIA DE DESIGUALDADE SOCIAL E ECONÔMICA PELA TEORIA RAWLSIANA DA JUSTIÇA}

De acordo com o que foi visto acima, nota-se que o desenvolvimento econômico deve ser incentivado para que se reduza a desigualdade social. O jurisfilósofo John Rawls, ao tratar da teoria da justiça, afirma que é possível a legitimidade da desigualdade social e econômica.

Assim, nesse item não temos a pretensão de abordar o complexo estudo da teoria ralwsiana de justiça, mas, sim, a sua exposição para que se compreenda a possibilidade da existência de desigualdade sem que isso macule a justiça.

"Uma teoria da justiça", escrita por John Rawls, foi publicada no Brasil nos idos de 1997, tendo sido dividida por três partes, em nove capítulos e setecentos e oito páginas. A primeira parte tratou da Teoria; a segunda das Instituições e a terceira sobre Objetivos. Essa obra resultou de várias anos de estudo e pesquisa, publicados como artigos autônomos, que, em seguida, foram reunidos num livro.

A teoria clássica do contrato social apresentada por Locke, Rousseau e Kant é revisitada por John Rawls, por isso, é considerado como neocontratualista contemporâneo. De fato, para ele o contratualismo não é aquele que inaugura uma determinada sociedade. Os princípios da justiça social é que serão levados em consideração para o consenso original.

O pensamento de Jonh Rawls está centrado em fundamentar uma sociedade livre e justa. Para Rawls a justiça é a primeira virtude das instituições sociais, ou seja, aquilo que a verdade é para a ciência, deve a justiça ser para as instituições sociais. Eis suas palavras: "A justiça é a primeira virtude das instituições sociais como a verdade o é dos sistemas de pensamento" (RAWLS, 2000, p. 3)

Para se criar uma sociedade justa é necessário saber como serão distribuído os bens e direitos que, pela Teoria da Justiça de Rawls, esses bens e direitos terão que ser 
distribuído por meio de regras e princípios justos. Isso é chamado pelo autor como justiça como equidade.

Em uma sociedade é normal que surjam entre os seus integrantes identidades de interesses como também conflitos de interesses. O acordar e o desacordar é natural em uma sociedade com direitos e deveres. As pessoas podem acordar ou discordar pelos mais vários motivos no tocante as formas de divisão dos direitos e deveres e dos benefícios e ônus gerados no convívio social.

Assim, como formular um conjunto de regras e princípios que permitem distribuir, de uma maneira justa, bens e direitos com a finalidade de construir uma sociedade justa.

Se perguntar para uma pessoa que já participa de uma sociedade, é notório que, ao se elaborar os princípios e regras basilares dessa nova sociedade, criar-se-iam princípios que, de certo modo, beneficiam a sua posição já escolhida. Cada grupo vai tentar ao máximo se beneficiar, ou seja, vai querer beneficiar seus próprios interesses. Não seriam, na verdade, regras justas e, consequentemente, não proporcionaria uma sociedade livre e justa.

Assim, diante desse conflito, Rawls parte da seguinte premissa: para resolver isso nós vamos ter que fazer um novo contrato social, propondo que as pessoas saiam de suas posições sociais para uma posição originária onde ele vai estar coberto com um véu de ignorância. Em outras palavras, não se saberá, nessa posição originária, quem ele é dentro da sociedade.

Jonh Rawls, sobre isso, escreve que:

... isso garante que ninguém é favorecido ou desfavorecido na escolha dos princípios pelo resultado do acaso natural ou pela contingência das circunstâncias sociais. Uma vez que todos estão numa situação semelhante e ninguém pode designar princípios para favorecer sua condição particular, os princípios de justiça são o resultado de um consenso ou ajuste equitativo (RAWLS, 2000, p. 13)

Se não souber de nada, poderá formular regras e princípios imparciais, justas e universais que sirvam a todos. Na posição original, sob o véu da ignorância, apresentarse-iam dois princípios que seriam escolhidos unanimemente pelos indivíduos.

Para Rawls, são os seguintes princípios da justiça social, também denominados de princípio da diferença:

Primeiro: cada pessoa deve ter um direito igual ao mais abrangente sistema de liberdades básicas iguais que seja compatível com um sistema semelhante de liberdade para as outras. Segundo: as 
desigualdades sociais e econômicas devem ser ordenadas de tal modo que sejam ao mesmo tempo: (a) consideradas como vantajosas para todas dentro dos limites do razoável, e (b) vinculadas a posições e cargos acessíveis a todos (RAWLS, 2000, p. 5).

Deveras, esses princípios são considerados como o alicerce da estrutura de uma sociedade politicamente organizada, concedendo direitos e obrigações aos seus integrantes. O primeiro concede os direitos básicos de todos os seres humanos, considerados como direitos de $1^{\circ}$ geração, ao passo que o segundo tenta regular e limitar a aplicação decorrente do primeiro princípio, compreendidos nos direitos de $2^{\circ}$ geração, corrigindo as desigualdades sociais e econômicas.

O primeiro princípio, portanto, refere-se as liberdades públicas básicas, que devem ser concedidas equitativamente a todos, tais como a liberdade de pensamento, liberdade de expressão, liberdade de propriedade privada, liberdade de reunião, liberdade de informação, dentre outros.

Por outro lado, o segundo princípio busca reduzir as desigualdades sociais. Note-se, porém, que para John Rawls é admitida a existência de desigualdade, desde que for garantida uma igualdade equitativa de oportunidades e se essas desigualdades resultarem em benefícios para todos e não só para aquele que se favorece.

Aliás, esclarece Eduardo Carlos Bianca Bittar:
A aplicação de ambos os princípios confirma continuamente a realização da justiça como equidade e igualdade. E isto sobretudo porque se trata de uma teoria que identifica as desigualdades naturais e procura corrigi-las. Deve-se mesmo, numa teoria que tenha este perfil, buscar-se romper a desigualdade natural entre as pessoas, para que assim se faça justiça. Mais que isto: os dois princípios devem se incumbir de fazer com que todos participem da melhor forma possível das estruturas sociais de forma que a estrutura cooperativa da sociedade facilite a manutenção de uma sociedade organizada" (BITTAR, 2000, p. 217).

Jonh Rawls menciona que "a ideia intuitiva é de que a ordem social não deve estabelecer e assegurar perspectivas mais atraentes dos que estão em melhores condições a não ser que, fazendo isso, traga também vantagens para os menos afortunados" (RAWLS, 2000, p. 80).

Em seguida, o mesmo autor destaca o objeto primário da justiça em uma estrutura básica de sociedade “... pela qual as instituições sociais mais importantes distribuem direitos e deveres e determinam a divisão de vantagens provenientes da cooperação social” (RAWLS, 2000, p. 8). 
No tocante ao desenvolvimento econômico e a redução da desigualdade, Jonh Rawls acrescenta que “... a desigualdade é justificável apenas se a diferença de expectativas for vantajosa para o homem representativo que está em piores condições" (RAWLS, 2000, p. 82).

Acrescentando que:

[...] todos se beneficiam quando o princípio da diferença é satisfeito. Pois o homem representativo que está em melhores condições em qualquer comparação de mão-dupla ganha pelas vantagens que lhes são oferecidas, e o homem em piores condições ganha por meio das contribuições originadas pelas desigualdades. [...] Mas nesse caso aqueles que estão em situação melhor não deveriam ter poder de veto em relação aos benefícios disponíveis para os menos favorecidos (RAWLS, 2000, p. 85).

A partir dos princípios estabelecidos por Rawls, as desigualdades que não estejam calcadas nela, dever sofrer uma correção, com o intuito de restaurar a igualdade e reduzir a desigualdade. Deve haver, portanto, uma forma de compensação. A forma de restabelecer a justiça nesta situação dá-se com o benefício mútuo de modo que “... o bem-estar de cada um depende de um esquema de cooperação social sem o qual ninguém teria uma vida satisfatória; reconhecem também que só podem esperar uma cooperação voluntária de todos se os termos do esquema forem razoáveis" (RAWLS, 2000, p. 110).

O Estado, ao buscar o equilíbrio entre o desenvolvimento econômico e a redução da desigualdade social, de certo forma busca atender ao princípio da diferença doravante analisado. As desigualdades econômicas existirão, de modo que, para reequilibrá-los no parâmetro da justiça, a distribuição de renda e outros incentivos políticos somente serão admitidas se favorecerem os que estão em desvantagem econômica e nunca o inverso.

Aliás, esclarecem Thadeu Weber, Cleidi Calgaro e Ana Paula Ludgren que “... as desigualdades são inerentes às sociedades, sejam em função dos diferentes talentos e capacidades, seja diante da necessidade de se minimizar a eficiência das estruturas econômicas e sociais (WEBER et al, 2014, p. 09).

Com a aplicação dos princípios, busca-se:

[...] estabilizar as diferenças (econômicas, sociais e naturais), redistribuindo o saldo de bens primários de forma em que os menos favorecidos da sociedade sejam beneficiados. Essa é a igualdade democrática dos bens primários sustentada por Rawls. Busca-se transformar os objetivos da estrutura básica, de modo que o esquema global das instituições enfatize menos a eficiência social e os valores 
tecnocráticos em detrimento das necessidades dos menos favorecidos. Destaca-se que as diferenças sociais são admitidas. O que não se admite são as desigualdades sociais discrepantes, estas não podem ser justificadas. Elas devem aceder a um modelo organizacional cooperativo em que todos possam contribuir para o desenvolvimento, sobretudo dos menos privilegiados (TRAMONTINA; PARREIRA, 2015, p. 280).

Nas palavras de Jonh Rawls o princípio da diferença compreende a "[...] ideia de não querer ter maiores vantagens, exceto quando isso traz benefícios para os outros que estão em pior situação" e que "as desigualdades econômicas e sociais devem ser ordenadas de modo a serem ao mesmo tempo (a) para maior benefício esperado dos menos favorecidos e (b) vinculadas a cargos e posições abertos a todos em condições de igualdade equitativa de oportunidades" (RAWLS, 2000, p. 88).

Ao explicar o princípio da diferença e a possibilidade de desigualdade da teoria da Justiça de Rawls, Marcelo Gollo Ribeiro escreve que:

a redução das desigualdades sociais naquilo pertinente a renda e a riqueza passam pela cooperação social equitativa dentro de uma estruturação das instituições e para a justiça distributiva de uma forma geral". Sendo que para analisar a justiça de uma sociedade deve ser verificada a quantidade de bens primários de que dispõem os menos favorecidos. Os princípios de justiça de Rawls "[...] têm a função de regular todos os acordos e formas de governo e os tipos de cooperação social, portanto, o papel das instituições é harmonizar as liberdades dos indivíduos garantindo as mesmas oportunidades básicas de um modo imparcial" (RIBEIRO, 2013, p. 10-11).

No mesmo sentido, Geraldo Neves Leite ao resumir a teoria da justiça de Rawls, ensina que:

[...] é desenvolvida a partir de uma ideia central de que todos os bens primários sociais - liberdade e oportunidade, renda e riqueza e as bases do autorrespeito - devem ser distribuídos igualmente, a menos que uma distribuição desigual de qualquer um ou de todos estes bens seja vantajosa para os menos favorecidos e em uma concepção de justiça baseada na existência de dois princípios de justiça social: o princípio da igualdade (igual liberdade básica para todos) e diferença (desigualdade social e econômica controlada) (LEITE, 2017, p. 117).

Amandino Teixeira Nunes Junior, corroborando o que foi dito até agora, consigna que:

[...] a teoria da justiça de Rawls busca integrar as liberdades civis e políticas com os direitos econômicos, sociais e culturais. Transformase em modelo para os governos socialdemocratas que se instalaram no mundo ocidental. Entre o liberalismo extremo e o socialismo ortodoxo, Rawls propõe uma alternativa intermediária, a que denomina "justiça como equidade" (justice as fairness). [...] desenvolve um amplo espectro de reflexões fundado na "equidade" (fairness) para orientar a ação política e a escolha em sociedades 
democráticas e que envolve, implicitamente, uma concepção alternativa de democracia. (NUNES JÚNIOR, 2005, p. 222)

Ato contínuo, o mesmo autor expõe que os princípios de Jonh Rawls “... regulam a escolha de uma Constituição política, devendo ser aplicados, em primeiro lugar, às profundas e difusas desigualdades sociais, supostamente inevitáveis na estrutura básica de qualquer sociedade." Logo em seguida, arremata que "os princípios da justiça rawlsianos são, pois, modelares das instituições e suficientemente significativos para a produção da liberdade, da igualdade e da solidariedade" (NUNES JUNIOR, 2005, p. 223).

Jonh Rawls acrescenta que a justiça em uma determinada sociedade “... depende essencialmente de como se atribuem direitos e deveres fundamentais e das oportunidades econômicas e condições sociais que existem no vários setores da sociedade" (RAWLS, 2000, p. 08).

Robison Tramontina e Anny Marie Santos sintetizam da seguinte forma:

em um ambiente marcado por fortes desigualdades sociais, a formulação de políticas públicas que visam a uma distribuição equitativa de bens primários passa a ser uma exigência moral. Rawls informa, com seu segundo princípio de justiça - da igualdade equitativa de oportunidade -, que o governo, principal a instituição social, deve: a) manter as formas habituais de despesas sociais básicas; b) assegurar oportunidades iguais de educação e cultura; c) assegurar oportunidades iguais nas atividades econômicas e na livre escolha do trabalho.. Elas formam uma plataforma mínima necessária para o um agir humano moral. A oferta desigual de tais bens viola a dignidade da pessoa humana. é com base nessa compreensão que as políticas públicas devem ser pensadas e formuladas (TRAMONTINA; SANTOS, 2015, p. 280-281).

Em uma aplicação prática da teoria da justiça de Jonh Rawls no direito brasileiro, é apresentado por Thadeu Weber, Cleidi Calgaro e Ana Paula Ludgren ao citarem o Plano Brasil sem Miséria. Eis suas palavras:

Isso se pode observar pelo fato do Plano objetivar a elevação da renda e as condições de bem-estar da população, além da melhoria de suas condições de participação na vida política, social e econômica do país, onde se verificam ações pautadas em três eixos de atuação como a garantia de renda, a inclusão produtiva e o acesso a serviços públicos. [...] Considerando a teoria Rawlsiana se observa que o compromisso assumido por esse Plano é democratizante e equitativo segundo o modelo do liberalismo igualitário e, com isso, tem-se claro a preocupação com os sujeitos "menos favorecidos" que necessitam de benefícios na sociedade brasileira. Assim, o Plano Brasil sem Miséria tem a preocupação em atender, sempre na medida do possível, todos os tipos de necessidades da população "menos favorecida", sem esquecer as diferença entre elas (WEBER et al, 2014, p. 11). 
Infere-se, assim, a teoria da justiça apresentada por Jonh Rawls tem o mérito de apresentar a justiça sob uma perspectiva diferente, pois passou a tratar de questões sociais e econômicas, "propiciando um novo tipo de igualitarismo teórico, um igualitarismo não mais de oportunidades, mas de resultados" (SILVA, 1998, p. 221).

Penso que a busca do desenvolvimento delineado nas linhas acima se encaixa nas premissas da teoria da justiça preconizada por Jonh Rawls, tendo em vista que um dos princípios da ordem econômica é a valorização principalmente da justiça social e da busca do pleno emprego. Não se busca um desenvolvimento econômico sem regras e sem fundamentos. Pelo contrário, por meio dele se busca atingir uma redução da desigualdade.

O Estado deve adotar medidas para incentivar o desenvolvimento econômico da mesma forma que também deve proporcionar, por meio de políticas públicas, uma melhor distribuição de renda, com o escopo de reduzir a desigualdade entre as pessoas de uma sociedade.

Por fim, encerra-se o presente item, mencionando-se o seguinte pensamento de Rawls: "Minha esperança é a de que a justiça como equidade pareça razoável e útil, mesmo que não seja totalmente convincente para uma grande gama de orientações políticas ponderadas, e portanto expresse uma parte essencial do núcleo comum da tradição democrática" (RAWLS, 2000, p. XIII-XIV).

Independentemente da opção adotada entre capitalismo ou quaisquer outro regimes econômicos, mister se faz a adoção da justiça como um superprincípio a irradiar seus efeitos em todas as facetas do Estado para que se promova o desenvolvimento econômico e, concomitantemente, a redução das desigualdades sociais.

\section{CONCLUSÃO}

$\mathrm{O}$ direito ao desenvolvimento trata-se de um direito humano inalienável em face do qual todos os seres humanos e todos os povos têm o direito de participar, de contribuir e de gozar do desenvolvimento econômico, social, cultural e político, no qual todos os direitos humanos e liberdades fundamentais se possam plenamente realizar.

Para tanto, o Estado deve se fazer presente no setor econômico para que as riquezas e os bens de produção nacionais proporcionem uma qualidade de vida à toda 
população, calcada no princípio distributivo, conciliando, dessa forma, a ordem econômica com a ordem social.

No entanto, o desenvolvimento econômico não deve ser um fim em si mesmo. Muito pelo contrário, de ver apenas um instrumento para que se reduza desigualdade social, em todos os seus aspectos, numa decorrência direta do princípio da dignidade da pessoa humana. A ordem econômica, portanto, deve se compatibilizar a ordem social.

O desenvolvimento econômico produz a produção de bens e de serviços e o desenvolvimento social determina a divisão das riquezas promovidas por aquele. Ao se compatibilizar ambos desenvolvimentos atingir-se-á a dignidade da pessoa humana e, por conseguinte, a redução das desigualdades sociais que constitui o objetivo da da República Federativa do Brasil.

A ordem econômica encontra-se pautada pela justiça social e, nesse aspecto, vai ao encontro das premissas da teoria da justiça proposto por John Rawls com a distribuição de riqueza e de renda, com oportunidades de acesso a todos os indivíduos de uma sociedade ordenada.

A justiça por equidade, ao se estabelecer um novo contrato social, deverá ter como ponto de partida a posição original, situação hipotética, em que se desconhece sua atuação na sociedade, todos em plena igualdade. Dessa forma, poderiam se estabelecer os princípios sem que ninguém seja favorecido ou desfavorecido.

No entanto, é evidente que sempre haverá desigualdades que precisarão ser corrigidas pelo sistema, admitindo-se apenas se for para a garantia de uma igualdade equitativa de oportunidades e se essas desigualdades resultarem em benefícios para todos e não só para aquele que se favorece.

A partir do momento em que a atividade econômica é regulada pelo Estado, ao regulamentá-la, a idéia de justiça de Rawls deve ser considerada como um superprincípio, ao lado do princípio da dignidade da pessoa humana, afastando, assim, o Estado utilitarista e imponto limites ao individualismo do homem.

O Estado deve adotar medidas para incentivar o desenvolvimento econômico e, ao mesmo tempo, deve proporcionar, por meio de políticas públicas, uma melhor distribuição de renda, com o escopo de reduzir a desigualdade entre as pessoas de uma sociedade.

\section{REFERÊNCIAS BIBLIOGRÁFICAS}


ANDRADE JÚNIOR, Gualter de Souza. Autonomia Privada: perspectiva do Estado de Direito Democrático. Belo Horizonte: Programa de Pós Graduação em Direito da Universidade Federal de Minas Gerais [Tese de Doutorado em Direito], 2010.

BITTAR, Eduardo Carlos Bianca. Teorias sobre a justiça: apontamentos para a história da filosofia de direito. São Paulo: J.Oliveira, 2000.

BILHALVA, Jaqueline Michels. A aplicabilidade e a concretização das normas constitucionais. Porto Alegre: Livraria do Advogado, 2005.

CANOTILHO, J.J. Gomes. Direito Constitucional. Coimbra, 1981, v. 2.

CATALISA. CATALISA - Rede de Cooperação para Sustentabilidade. 2020.

Disponível em: https://catalisa.org.br/2018/. Acesso em: 09 nov. 2020

COELHO, Paulo de Oliveira Pinto; ARAUJO, Andre Fabiano Guimarães de. $A$ sustentabilidade como Princípio Constitucional Sistêmico e sua relevância na efetivação interdisciplinar da ordem constitucional econômica e social: para além do ambientalismo e do desenvolvimento. Revista da Faculdade de Direito, v. 39, p 213, 2011 ,

GRAU, Eros Roberto. A ordem econômica na Constituição de 1988. São Paulo: Malheiros, 2018.

FIGUEIREDO, Leonardo Vizeu. Lições de Direito Econômico. Rio de Janeiro: Forense, 2012.

HECK, Luiz Afonso. "Prefácio". In: ROCHA SCOTT, Paulo Henrique. Direito Constitucional Econômico. Estado e Normalização da Economia. Porto Alegre: Safe, 2000 .

LAFER, Celso. Comércio, Desarmamento, Direitos Humanos: reflexões sobre uma experiência diplomática. São Paulo: Paz e Terra, 1999.

LEITE, Geraldo Neves. O princípio da eficiência na teoria de justiça como equidade de Rawls. 2017. Disponível em: <ttps://www.conpedi.org.br/

publicacoes/27ixgmd9/mgg256zf $>$. Acesso em: 06 nov. 2020

LENZA, Pedro. Direito Constitucional Esquematizado. São Paulo: Saraiva, 2018.

MASSO, Fabiano Del. Direito Econômico Esquematizado. Rio de Janeiro: Forense, 2012.

NAZAR, Nelson. Direito Econômico. Bauru: Edipro, 2009.

NOBRE, Marcos; AMAZONAS, Maurício de Carvalho. Desenvolvimento sustentável: a institucionalização de um conceito. Brasília: Edições IBAMA, 2002. 
NUNES JUNIOR, Amandino Teixeira. A teoria rawlsiana da justiça. 2005. Disponível em: < http://www2.senado.leg.br/bdsf/item/id/573>. Acesso em: 06 nov. 2020.

ORGANIZAÇÃO DAS NAÇÕES UNIDAS. Nosso futuro comum. 2. ed. Rio de Janeiro: Fundação Getúlio Vargas, 1991.

PEREIRA, Antonio Celso Alves. "O direito ao desenvolvimento no contexto dos direitos humanos". In: Boletim da Sociedade Brasileira de Direito Internacional, Janeiro/Março, 1992, nº 77/78, p. 29.

PETTER, Lafayete. Direito econômico. Porto Alegre: Verbo Jurídico, 2011

RAWLS, John. Uma teoria da justiça. São Paulo: M. Fontes, 2000

RIBEIRO, Marcelo Gollo. A distribuição de rendimentos: um paralelo entre Rawls e Nozick. 2013. Disponível em: < https://jus.com.br/artigos/25663/adistribuicao-de-rendimentos-um-paralelo-entre-rawls-e- nozick/2 > . Acesso em: 06 nov. 2020

SCOTT, Paulo Henrique Rocha. Direito Constitucional Econômico: Estado e normalização da Economia. Porto Alegre: Sergio Antonio Fabris, 2000

SAYEG, Ricardo Hasson. Perfil Constitucional do Capitalismo Humanista Brasileiro. In: FILHO, Ives Granda da Silva Martins; MEYER-PFLUG, Samantha Ribeiro (coord.). A intervenção do Estado no domínio econômico: condições e limites. São Paulo: LTr, 2011.

SEN, Amartya. Desenvolvimento como liberdade, São Paulo: Companhia da Letras, 1999.

SILVA, Ricardo Perdingeiro Mendes da. Teoria da justiça de John Rawls. Revista de Informação Legislativa, Brasília, a. 35, n. 135, p. 193-212, abr/jun, 1998.

RISTER, Carla Abrantkoski. Direito ao Desenvolvimento - antecedentes, significados e consequências. Rio de Janeiro: Renovar, 2007.

TAVARES, Andre Ramos. Direito constitucional. São Paulo: Saraiva, 2002.

TRAMONTINA, Robison; PARREIRA, Anny Marie Santos. A Teoria da Justiça de John Rawls como aporte teórico para a formulação e a avaliação de Políticas Públicas. Revista da AJURIS, Porto Alegre, v. 42, n. 139, dez. 2015. Disponível:

$<$ http://www.ajuris.org.br/OJS2/index.php/

REVAJURIS/article/viewFile/487/Ajuris_139_DT11.pdf>. Acesso em: 06 out. 2020. WEBER, Thadeu; CALGARO, Cleidi; LUDGREN, Ana Paula. A justiça distributiva em John Rawls e o Plano Brasil sem Miséria: análise das políticas públicas a partir da Constituição Federal de 1988 como garantia dos direito fundamentais de igualdade, 
liberdade e busca da cidadania. In: XII Seminário Internacional de Demandas Sociais e Políticas Públicas na Sociedade Contemporânea. Universidade de Santa Cruz do Sul. 2014. Disponível em: <http://online.unisc.br/acadnet/anais/index.php/ sidspp/article/view/11723>. Acesso em: 09 nov. 2020. 